\title{
Characteristics of Female Students Who Aspire to Science and Engineering or Homemaking Occupations
}

\author{
Wei-Cheng Mau, Margaret Domnick, Randolph A. Ellsworth
}

This study identified predictors that discriminated between nontraditional and traditional career aspirations in a sample composed of 930 eighth-grade female students (52 Asian Americans, 123 Hispanics, 61 African Americans, 669 Whites, and 15 Native Americans). Results indicated that the students who aspired to careers in science or engineering scored significantly higher on educational aspirations; perceived parental expectations; student-reported grade point averages (GPAs); and mathematics, reading, and science test scores than did girls who aspired to homemaking occupations. They also scored higher on measures of self-esteem, internal locus of control, socioeconomic status, and had fewer siblings. Educational aspirations, parental expectations, selfreported GPA, and science proficiency were the best discriminators between the groups. Results also indicated that differences in the distributions of career aspirations across racial-ethnic groups were significant.

Nontraditional occupations have been defined as those having less than 30\% to $34 \%$ women among their ranks (Hayes, 1985). Science, engineering, technical, and managerial occupations typically meet this definition. The underrepresentation of women in these male-dominated occupations has prompted numerous researchers to study the characteristics of women who work in nontraditional occupations. Baker (1987) and MacCorquodale (1984) reported that nontraditional career-oriented women described themselves as self-confident, very competitive, and either highly independent or highly dependent. Other nontraditional career-oriented women indicated that they received direct 
encouragement from teachers, counselors, and significant others (e.g., Dick \& Rallis, 1991; Fitzpatrick \& Silverman, 1989; Sloat, 1990); have working mothers as role models (Almquist, 1974); have parents with higher education and occupational levels (McKenna \& Ferrero, 1991); and come from higher socioeconomic-level homes (Berman, 1972; McKenna \& Ferrero, 1991). Women aspiring to nontraditional careers are often firstborn or only children (McKenna \& Ferrero, 1991; Rea-Poteat \& Martin, 1991), hold fewer traditional attitudes toward women, and perceive less conflict between combining work and family (Murrell, Frieze, \& Frost, 1991; Rubenfeld \& Gilroy, 1991). The more stereotypical masculine characteristics (as defined by Bern, 1974) a woman perceives herself to have, the more likely she is to choose a nontraditional career (Baker, 1987).

The aforementioned findings provide rather simplistic descriptions and are not as conclusive as they might seem to be (Herr \& Cramer, 1988). The studies provide information about variables associated with women's aspirations to nontraditional careers, but give no . information about the significance of each variable in comparison with the others and do not indicate how these variables interrelate and contribute to the choices that women make when choosing nontraditional occupations.

This investigation differs in several ways from previous studies dealing with career aspirations. First, most previous studies focused on working women (e.g., Berman, 1972; Mazen \& Lemkau, 1990; Stewart, 1989) whereas in this study, "occupation aspired to" rather than "occupation entered" is used as a criterion. Pryor (1981) and others (Haring \& Beyard-Tyler, 1984; Pryor \& Taylor, 1986) have argued that "expressed choice" has more "psychological utility" than the more commonly used criterion of occupational entry. Expressed choice or aspired occupation is a psychological criterion, which represents an individual's career choice before consideration of situational variables such as job availability or financial responsibility.

Second, eighth-grade girls' aspirations were studied. Most of the research investigating nontraditional careers focused on high school students or college-age students. Eighth-grade students typically are in the crucial stage of exploring self and the world of work (Super, 1969). Unlike some occupational fields, preparation for nontraditional occupations, especially in the areas of science and engineering, must begin early. As pointed out by Smith (1980), training in math and science needs to be sequential and uninterrupted from elementary school, and fundamentals must be mastered before high school.

Third, although many occupations could be considered nontraditional for women, this study focuses on science and engineering occupations. These areas were chosen because women are still underrepresented in the quantitative-based disciplines at all degree levels. Hilton and Lee (1988) indicated that although there have been significant increases in the number of female students interested in quantitative-based disciplines from 1972 to 1982, men still outnumber women by more than 2 to 1 . Thus, this study investigated the relative importance of some of the previously identified variables for predicting which eighth-grade girls aspire to nontraditional occupations. The following two basic questions were addressed:

1. Which independent variables in the National Educational Longitudinal Study of 1988 (NELS:88) best discriminate between girls who aspire to homemaking occupations and girls who aspire to science and engineering occupations?

2. Do certain variables have differential predictive power for girls from different racial-ethnic groups? 
Independent variables in this study were chosen from the set available in the NELS:88 including self-esteem, locus of control, educational aspiration, perceived parents' educational expectations, academic proficiency, socioeconomic status, and number of siblings. These variables have been discussed in the literature and have been considered important in predicting occupational attainments (e.g., Blau \& Duncan, 1967; Kerckhoff, 1989; Otto \& Hailer, 1979; Sewell \& Hauser, 1980). For our study, the dependent variable became group membership (science/engineering rs. homemaking), and racial-ethnic differences were investigated through a nationally representative sample of eighth-grade girls composed of Asian American, African American, Hispanic, Native American, and White students.

\section{METHOD}

This study involved a sample of 930 eighth-grade female students who aspired to either science- or engineeringrelated occupations or who were interested in traditional homemaker roles. The racial-ethnic makeup of this sample consisted of 52 Asian American, 123 Hispanic, 61 African American, 669 White, and 15 Native American students. The data were obtained from the National Educational Longitudinal Study of 1988 (NELS:88) sponsored by the National Center for Educational Statistics

(NCES, 1990a). NELS:88 is the third and most recent in a series of longitudinal studies designed to provide timely information on trends in academic achievement.

A two-stage probability design was used in the NELS: 88 to ensure a nationally representative sample of schools and students. For the first stage, a stratified sampling of 1,734 public and private schools was selected, of which 1,052 participated. The second stage included random samples of $25(+/-1)$ students per sampled school, which resulted in a sample of 24,599 eighth-grade boys and girls. The school sample was stratified by size, urban versus rural, region, and percent minority population. Samples were weighted to compensate for unequal probabilities of selection and to adjust for nonresponse rates.

Asian American and Hispanic students were oversampled to produce adequate sample sizes for subgroup analyses. Much more specific detail of the sampling procedure is provided by the National Center for Educational Statistics (1990b).

Of the 24,599 randomly sampled eighth-grade students, 930 girls who aspired to either science or engineering occupations or homemaker work were selected for this study. They were selected on the basis of their response to the NELS:88 survey question: "What kind of work do you expect to be doing when you are 30 years old?" Total responses (boys and girls) for each option were craft person or operator (934), farmer or farm manager (198), housewife/homemaker (535), laborer or farm worker (116), military, police, or security officer $(2,121)$, professional, business, or managerial $(7,107)$, owning a business or service establishment (1,507), technical (1,434), salesperson, clerical, or of-rice worker $(650)$, science or engineering $(1,501)$, service worker $(1,099)$, other $(3,928)$, not working $(48)$, and don't know $(2,506)$. There were 473 multiple responses and 440 missing.

\section{Instruments}

Students who participated in the NELS:88 completed a 45-minute self-administered questionnaire in their classrooms. The questionnaire collected information about a wide range of topics, including students' and parents' backgrounds, perception of self, students' educational and vocational activities, postgraduation plans, and aspirations. Students also completed an 85-minute battery of cognitive 
tests (reading, mathematics, science, and social studies). The variables selected for this study included (a) educational aspirations, (b) perceived educational expectation of father, (c) perceived educational expectation of mother, (d) self-reported GPA, (e) socioeconomic status, (f) locus of control, (g) self-esteem, (h) number of siblings in student's own family, (i) math proficiency, (j) reading proficiency, and (k) science proficiency.

Educational aspirations. This variable was measured by the survey question: "As things stand now, how far in school do you think you will go?" Responses were coded from I to 6 as follows: 1 = won't finish high school, $2=$ will graduate from high school, $3=$ will go to vocational school, $4=$ will attend college, $5=$ will graduate from college, and 6 = will attend a higher level of school after graduating from college. Higher scores represent higher aspiration levels.

Perceived parents' expectations. The same response categories and coding were used for students' perceptions of their parents' expectations. Students recorded their perceptions for each parent separately as they responded to the question, "How far in school do you think your father and your mother want you to get?"

Math, science, and reading proficiency. These three variables were measured by three cognitive tests developed by Educational Testing Service (mathematics, 40 items; science, 25 items; and reading, 21 items). According to the Psychometric Report for the NELS: 88 Base Year Test Battery

(NCES, 1991), the primary purpose of this test battery was "to obtain an accurate measurement of the status of individuals at a given point in time as well as their growth over time" (p. 3). The reading test consisted of five short passages followed by comprehension and interpretation questions. The values for reading proficiency were as follows: 1 = below first level, 2 = at first level, and 3 = at second level. Science questions were constructed to assess science knowledge and science reasoning. The science test was scored by quartiles as follows: $1=$ first quartile, 2 second quartile, $3=$ third quartile, and $4=$ fourth quartile. The mathematics test consisted of quantitative comparisons and other questions. Overall mathematics proficiency was reported as follows: $1=$ below first level, 2 = at first level, $3=$ at first and second levels, and $4=$ proficient at all 3 levels.

Coefficient alpha reliabilities on the eighth-grade sample for the math, science, and reading tests were .90, .75, and .84, respectively. Based on the Mantel-Haenszel odds-ratio analyses (Holland \& Thayer, 1986), there was little evidence of differential item functioning for either gender or racial-ethnic group. Factor analytic results supported the construct validity of the hypothesized factors in these proficiency tests. More detailed psychometric information can be found in the NCES's (1991) Psychometric Report for the NELS: 88 Base Year Test Battery.

Socioeconomic status (SES). SES is a composite score based on parent's education, occupation, and family income. Parental education ranged from 1 (did not finish high school) to 6 (doctoral or other graduate degree). Occupational data were recorded using the Duncan SEI scale. Family income data were based on the total family income in 1987. Income level ranged from 1 (none) to 15 (\$200,000 or more). Each component was standardized with a mean of 0 and a standard deviation of 1 . All components were averaged to yield the SES composite. The composite scores were then converted to quartiles (see NCES, 1990a).

Locus of control (LC). The locus of control scale contained six items (e.g., "In my life, good luck is 
more important than hard work for success." "My plans hardly ever work out, so planning only makes me unhappy.") each rated on a 4-point Likert scale ranging from 1 (strongly agree) to 4 (strongly disagree). This scale has been used in the National Longitudinal Study of the High School Class of 1972 (NLS-72; NCES, 1981) and High School and Beyond (HS\&B; NCES, 1982). A higher score represents a strong belief that one is in charge of one's life. The scale had a coefficient alpha of .68 for the eighth-grade sample.

Self-esteem (SC). The self-esteem scale, derived from Rosenberg (1965), consisted of seven items (e.g., "I feel good about myself." "I feel I am a person of worth, the equal of other people.") each rated by students on a 4point Likert scale with a high score indicative of high self-esteem. This scale was designed to be comparable with HS\&B and NLS-72 studies and produced a coefficient alpha of .78 for the eighth-grade sample.

School grades (GPA). The school grade variable represents an average of self-reported grades for English, mathematics, science, and social studies. These self-reported grades were converted into. quartiles.

\section{Data Analysis}

Differences in the distributions of nontraditional and traditional career choices across racial-ethnic groups were analyzed using a 2 x 5 chi-square test of independence. Discriminant analysis (Klecka, 1980) was used to identify those variables useful in predicting which female students aspire to nontraditional or traditional occupations. Because this was an exploratory study, no priority was given to one variable over others in determining order of entry. All predictors entered the equation simultaneously and each predictor was assigned only the unique association it had with the two groups (nontraditional career aspiration or traditional career aspiration). Of the 930 cases, 10 cases were excluded because of missing racial background information. The prior probabilities of group membership were weighted based on the sample proportion of cases actually falling into each group.

\section{RESULTS}

A significant chi-square value was obtained, $\operatorname{chi}^{2}(4, \mathrm{~N}=920)=32.0, \mathrm{p}<.00001$, indicating differences among racial-ethnic groups in the distribution of science or engineering (SE) and homemaking (HM) career aspirations. Overall, more female students in this sample aspired to HM occupations $(\mathrm{n}=507 ; 55.1 \%)$ than to SE occupations $(n=413 ; 44.9 \%)$. Among racial-ethnic subgroups, however, Asian American $(n=38 ; 73.1 \%)$ and African American students $(\mathrm{n}=40 ; 65.6 \%)$ had higher percentages of SE career aspirations than HM career aspirations, whereas Hispanic $(n=46 ; 37.4 \%)$, White $(n=283 ; 42.3 \%)$, and Native American $(n=6 ; 40.0 \%)$ students had lower percentages of SE career aspirations than HM career aspirations.

Table 1 provides $\mathrm{F}$ tests of HM and SE group means by racial-ethnic group for each discriminant variable. The Native American group was not included because of small sample size $(\mathrm{HM}=9, \mathrm{SE}=6)$. Regardless of a student's racial background, students with SE career aspirations scored significantly higher on all variables, except the number of siblings, than did those with HM career aspirations. Students with SE aspirations, on the average, had higher scores for socioeconomic status, internal locus of control, self-esteem, educational aspirations, perceived parents' educational expectations and mathematics, reading, and science proficiency test scores. Students with SE 
aspirations also reported a higher overall grade point average, but they had fewer siblings in their families than HM aspiration students.

Patterns among each racial-ethnic subgroup were similar. With only one racial-ethnic group exception, SE aspiration students scored significantly higher than HM aspiration students on all variables except number of siblings in their families. The one exception was in the Asian American group in which SE aspiration students scored significantly higher than HM aspiration students only on measures of self-esteem, educational aspiration, science proficiency test, and self-reported GPA. The other nonsignificant differences between the HM and SE groups were, however, in the same direction as those of the other ethnic groups.

Table 2 provides standard canonical discriminant function coefficients, eigenvalues, loadings, canonical correlations, Wilks's lambdas, and chi-square values by racial-ethnic group as well as totals. Results from the separate discriminant analyses indicated reliable associations between aspiration groups and predictors for the Asian American, $\operatorname{chi}^{2}(7)=36.46, \mathrm{p}<.0001 ;$ Hispanic, chi $^{2}(5)=63.08, \mathrm{p}<.0001$;

African American, $\mathrm{chi}^{2}(4)=54.15, \mathrm{p}<.0001$; and White, $\mathrm{chi}^{2}(6)=257.67, \mathrm{p}<.0001$ groups. As expected, there was also a reliable association between predictors and aspiration groups for the total sample of female students, $\operatorname{chi}^{2}(7)=375.47, \mathrm{p}<.0001$.

Eigenvalues, as can be seen in Table 2, represent the ratio of the between-group to within-group sum of squares. The larger the eigenvalues the better the discriminant function. In fact, the coefficients of the discriminant functions are chosen so that the ratio of the between-group sum of squares to the within-group sum of squares is as large as possible. Asian American (.75) and African American (.80) groups had larger eigenvalues than other groups, indicating the discriminant functions were relatively better for these two groups. The White group had the smallest eigenvalue (.57).

Wilks's lambda represents the ratio of the within-group sum of squares to the total sum of squares. Small values of lambda are associated with functions that have much between-group variability and little within-groups variability. As can be seen in Table 2, Asian American (.44) and African American (.36) groups had smaller lambda values than Hispanic (.58) and White (.68) groups.

The canonical correlations indicate the degree of association between the discriminant scores and the groups. When squared, these correlations indicate the proportion of variance shared between groups and predictors on that function. The squared canonical correlations for Asian American, Hispanic, African American, White, and total are $.56, .42, .64, .32$, and .34 .

The standardized canonical discriminant function coefficients (SCDFC), often used to indicate the relative importance of predictors, are also presented in Table 2. Variables with large coefficients are thought to contribute more to the overall discriminant function. The most important predictor for the Asian American group was science quartile (-1.37), whereas educational aspiration is the most important predictor for Hispanic (.57), African American (.77), and White (.78) groups. The actual signs of the coefficients are arbitrary.

The loading of correlations between predictors and discriminant function, as seen in Table 2, indicates the performance of predictors for distinguishing between SE and HM aspiration groups. A loading value exceeding .50 is considered to be a good predictor (Tabachnick \& Fidell, 1989). For the Asian 
American group, the science quartile (.51) is the only predictor with a loading higher than .50 . The best predictor for the Hispanic group is students' educational aspirations (.81). Educational aspiration (.77) and math proficiency (.55) are the two best predictors for the African American group. Educational aspiration (.87), math proficiency (.50), and science quartile (.59) are the best predictors for the White group. For the total female sample, educational aspiration (.90), perceived mother's educational expectation (.52), science quartile (.52), and self-reported GPA (.50) are the best predictors.

To estimate how well these variables discriminate between SE and HM groups, percent-correct classification rates were calculated. For this sample of 930 female students, 695 (74.7\%) are classified correctly, compared with 511 (55.0\%) who would be classified correctly by chance alone. Percent-correct and chance (in parenthesis) classifications for the Asian American, Hispanic, African American, and White groups are 85\% (61\%), 81\% (54\%), 90\% (55\%), and 77\% (51\%). These results indicate that the variables are better than chance in discriminating between the groups.

The stability of the classification procedure was checked by a cross-validation analysis. Of the total female sample ( $\mathrm{n}=930), 621$ cases (approximately 66\%) were withheld from calculation of the classification functions in this run. For the $33 \%$ of the cases $(n=309)$ from which the functions were derived, correct classification rate was $76.38 \%$. For the cross-validation cases $(n=621)$, classification rate was $76.01 \%$. This indicates a high degree of consistency in the classification scheme. Cross-validation was not conducted for individual racialethnic groups because of the small sample sizes that would have resulted from splitting the groups.

\section{DISCUSSION}

The purpose of this study was to investigate a set of predictors that might provide discrimination power for differentiating between female students who aspire to homemaking and science or engineering occupations. Results of this study, although direct, must be interpreted carefully because of the nature of self-reported data and measurement error associated with limited items, for example, locus of control. Although science and engineering are considered to be nontraditional occupations for women, there are other occupations that are also underrepresented by women and minorities, and readers should be cautious in making generalizations to other nontraditional occupations.

Results of this study indicate that educational aspirations, perceived parental expectations, self-reported GPA, and science quartile are the best discriminators between science or engineering and homemaking groups. Although prior research has indicated the important effects of socioeconomic status (e.g., Berman, 1972; McKenna \& Ferrero, 1991) and self-concept (e.g., Baker, 1987; MacCorquodale, 1984) on women engaging in science and engineering careers, our findings suggest that students' educational aspirations, perceived parental expectations, academic proficiency (i.e., science, math), and self-reported GPA may have greater influence. Educational aspiration had a higher loading on the discriminant function than any other variable, and academic proficiency variables had higher loadings than socioeconomic status and self-concept variables. This pattern tends to be consistent across racial-ethnic groups except for Asian Americans for whom science proficiency was the best predictor. Educational aspirations and academic proficiency seem to be interrelated. 
Considering that educational aspirations and expectations were the best predictors for most of the students who aspired to science and engineering occupations, counselors and educators could use this information in identifying students who may be interested in science-engineering occupations. Smith (1980) proposed a counseling model for working with such students that involved a sequence of interventions at different levels. The first intervention level would be directed toward students' skill attainment during elementary school, the second level, career awareness and planning, and the third intervention level, direct counseling of students and counselor consultation with teachers, scientists, and engineers. This model may not be applicable to all racial minority groups, however. Counselors need to take into consideration the cultural perspective of each ethnic group with which they are working.

According to Smith (1980), part of the reason for low percentages of minorities involved in science and engineering is their low academic proficiency in these areas. Mau's study (in press) indicated that eighth-grade students' academic achievements are positively associated with their educational aspirations. Other studies (e.g., Duran \& Weffer, 1992; Hanson \& Ginsburg, 1988) also indicated that students' expectations of going to college, or parental expectations of a child going to college, have a greater impact than socioeconomic factors on students' academic proficiency. In other words, high academic achievement tends to promote high educational aspiration, or vice versa. Riley (1993) suggested that higher academic expectations for all students, regardless of background or socioeconomic status, is critical in moving education forward. How to motivate students to learn and to aspire to higher educational goals is an important question.

The findings of this study are encouraging in that a relatively large number of African American female students aspired to science and engineering occupations. The fact that most African American mothers are working (U.S. Department of Labor, 1988) may influence them to become career oriented. Perhaps lack of role models is another reason why fewer percentages of Hispanic, Native American, and White students aspire to science and engineering occupations. Providing role models for female students may be important to facilitate career-oriented individuals.

Counselors need to attend to the special obstacles and potential "leakage points" when helping students prepare for science and engineering careers. Obstacles likely to be experienced by women and minorities include (a) low self-esteem and low career self-efficacy, particularly concerning math and science abilities (American Association of University Women, 1991; Haring \& Beyard-Tyler, 1984; Nevill \& Schlecker, 1988); (b) gender role stereotyping (Brooks, 1984; Fitzgerald \& Betz, 1983); and (c) lack of support services and isolation in the classroom (McBride-Bass, 1993).

There are several leakage points along the educational pipeline where students are lost from quantitative fields. Hilton and Lee (1988) indicated that two major leakage points occur when students move from high school to college and from college to graduate school. Early commitment and preparation for science and engineering careers seems to be critical because the greatest loss point is in the transition from high school to college. Recognizing that the majority of high school students do not enter or complete college, other options that lead to quantitative fields may be viable. In a recent American Counseling Association position paper, Herr (1992) asserted that work-bound students are not inferior. Instead, these students constitute an important proportion of the workforce and their needs must be given national and local priority. The Perkins Act also advocates programs such as 
Locus of control

$\begin{array}{lllllll}\text { M } & 18.1 & 17.5 & 0.4 & 18.1 & 16.2 & 13.2 \text { [c] }\end{array}$

$\begin{array}{llllll}18.4 & 16.0 & 11.9[\mathrm{c}] & 19.2 & 17.3 & 58.8[\mathrm{~d}]\end{array}$

$18.8 \quad 17.0 \quad 78.3[\mathrm{~d}]$

$\mathrm{SD} \quad 2.6 \quad 4.3 \quad--\quad 3.0 \quad 3.0 \quad--$

$2.6 \quad 2.7^{--} \quad 2.9 \quad 3.1^{--}$

$2.93 .1--$

Self-esteem

$\begin{array}{lllllll}M & 22.4 & 19.9 & 5.3[*] & 21.8 & 20.0 & 9.6[* *]\end{array}$

$23.0 \quad 21.0 \quad 5.4[*] \quad 21.6 \quad 20.3 \quad 23.2$ [d]

$21.8 \quad 20.3 \quad 46.1[\mathrm{c}]$

$\mathrm{SD} \quad 3.3 \quad 4.1 \quad--\quad 3.3 \quad 3.0 \quad--$

$3.13 .0--3.5 \quad 3.7 \quad--$

$3.53 .6--$

Educational aspiration

$\begin{array}{lllllll}M & 5.5 & 4.5 & 10.0[*] & 5.1 & 3.2 & 51.5\end{array}$

$\left.\begin{array}{lllllll}5.4 & 3.0 & 76.7 & {[d]} & 5.3 & 3.8 & 223.7\end{array}\right]$

$5.3 \quad 3.7 \quad 354.8[\mathrm{~d}]$

$\mathrm{SD} \quad 0.7 \quad 1.5 \quad--\quad 1.1 \quad 1.5 \quad--$

$0.8 \quad 1.5 \quad--0.8 \quad 1.5 \quad--$

$0.91 .5 \quad--$

Father's expectation

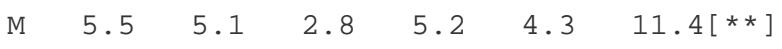

$\begin{array}{lllllll}5.3 & 4.6 & 6.0[*] & 5.3 & 4.6 & 53.0 & \text { [d] }\end{array}$

$5.3 \quad 4.6 \quad 92.5[\mathrm{~d}]$

SD $0.7 \quad 0.5 \quad--\quad 1.0 \quad 1.3 \quad--$

$0.9 \quad 1.2 \quad--0.8 \quad 1.1 \quad--$

$0.81 .1--$

Mother's expectation

$\begin{array}{llllllll}\text { M } & 5.4 & 5.2 & 0.9 & 5.2 & 4.4 & 11.1 & \text { [c] }\end{array}$

$\begin{array}{llllllll}5.5 & 4.2 & 19.8 & \text { [d] } & 5.3 & 4.6 & 65.2 & \text { [d] }\end{array}$ 
$5.3 \quad 4.6 \quad 113.2[d]$

SD $0.8 \quad 0.6 \quad--\quad 0.8 \quad 1.3 \quad--$

$0.7 \quad 1.4 \quad--\quad 0.8 \quad 1.1 \quad--$

$0.8 \quad 1.1 \quad--$

Math

$\begin{array}{lllllll}\text { M } & 3.1 & 2.8 & 0.5 & 2.6 & 2.0 & 12.2[\mathrm{C}]\end{array}$

$\begin{array}{llllllll}2.7 & 1.5 & 37,2 & {[d]} & 3.1 & 2.5 & 68.2 & \text { [d] }\end{array}$

$3.0 \quad 2.4 \quad 94.9[\mathrm{~d}]$

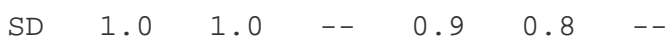

$\begin{array}{llllll}0.8 & 0.7 \quad-- & 0.9 & 1.0 \quad--\end{array}$

$0.9 \quad 1.0 \quad--$

Reading

$\begin{array}{lllllll}\text { M } & 2.4 & 2.1 & 1.7 & 2.2 & 1.9 & 5.4[*]\end{array}$

$\begin{array}{llllllll}2.3 & 1.8 & 7.1 & {[* *]} & 2.6 & 2.3 & 46.6 & \text { [d] }\end{array}$

$2.5 \quad 2.156 .8 \quad[d]$

$\begin{array}{lllllll}\text { SD } & 0.7 & 0.6 & -- & 0.7 & 0.7 & --\end{array}$

$\begin{array}{llllll}0.7 & 0.5 & -- & 0.5 & 0.7 \quad--\end{array}$

$0.6 \quad 0.7 \quad--$

Science

$\begin{array}{lllllll}M & 3.1 & 1.9 & 15.3[\mathrm{c}] & 2.4 & 2.0 & 7.0[* *\end{array}$

$\begin{array}{lllllll}2.6 & 1.4 & 20.3[d] & 3.3 & 2.5 & 97.8 & {[d]}\end{array}$

$\begin{array}{lll}3.1 & 2.3 & 118.9[\mathrm{~d}]\end{array}$

SD $1.1 \quad 0.8 \quad--\quad \begin{array}{lllll}1.1 & 0.9 & --\end{array}$

$\begin{array}{llllll}1.2 & 0.7 & -- & 0.9 & 1.0 & --\end{array}$

$1.0 \quad 1.1--$

GPAC

$\begin{array}{llllllll}M & 3.2 & 2.4 & 5.8\left[{ }^{*}\right] & 3.0 & 2.1 & 21.3 & \text { [d] }\end{array}$

$\begin{array}{lllllll}3.1 & 2.2 & 10.1[* *] & 3.3 & 2.6 & 54.5 & {[\mathrm{~d}]}\end{array}$

$\begin{array}{llll}3.2 & 2.4 & 103.8 \quad[d]\end{array}$

SD $\quad \begin{array}{llllll}1.0 & 1.1 & -- & 0.9 & 1.1 & --\end{array}$ 
$1.0 \quad 1.1 \quad--1.0 \quad 1.2 \quad--$

$1.0 \quad 1.2 \quad--$

Number of siblings

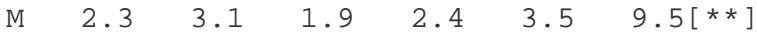

$\begin{array}{llllll}2.6 & 3.4 & 7.3[* *] & 2.1 & 2.7 & 29.4[\mathrm{c}]\end{array}$

$2.2 \quad 2.9 \quad 45.9[\mathrm{~d}]$

$\mathrm{SD} \quad 1.6 \quad 1.5 \quad--\quad 1.5 \quad 1.7 \quad--$

$\begin{array}{llllll}1.6 & 1.9 & -- & 1.3 & 1.6 & --\end{array}$

$1.4 \quad 1.7 \quad--$

a $\mathrm{SE}=$ Science or engineering aspiration group. $\mathrm{b} \mathrm{HM}=$ Homemaking aspiration group. $\mathrm{C}$ GPA $=$ grade point average.

${ }^{*} p<.05 .{ }^{* *} p<.01 .[c] p<.001 .[d] p<.0001$.

TABLE 2 Standardized Canonical Discriminant Function Coefficients and Loadings by Race

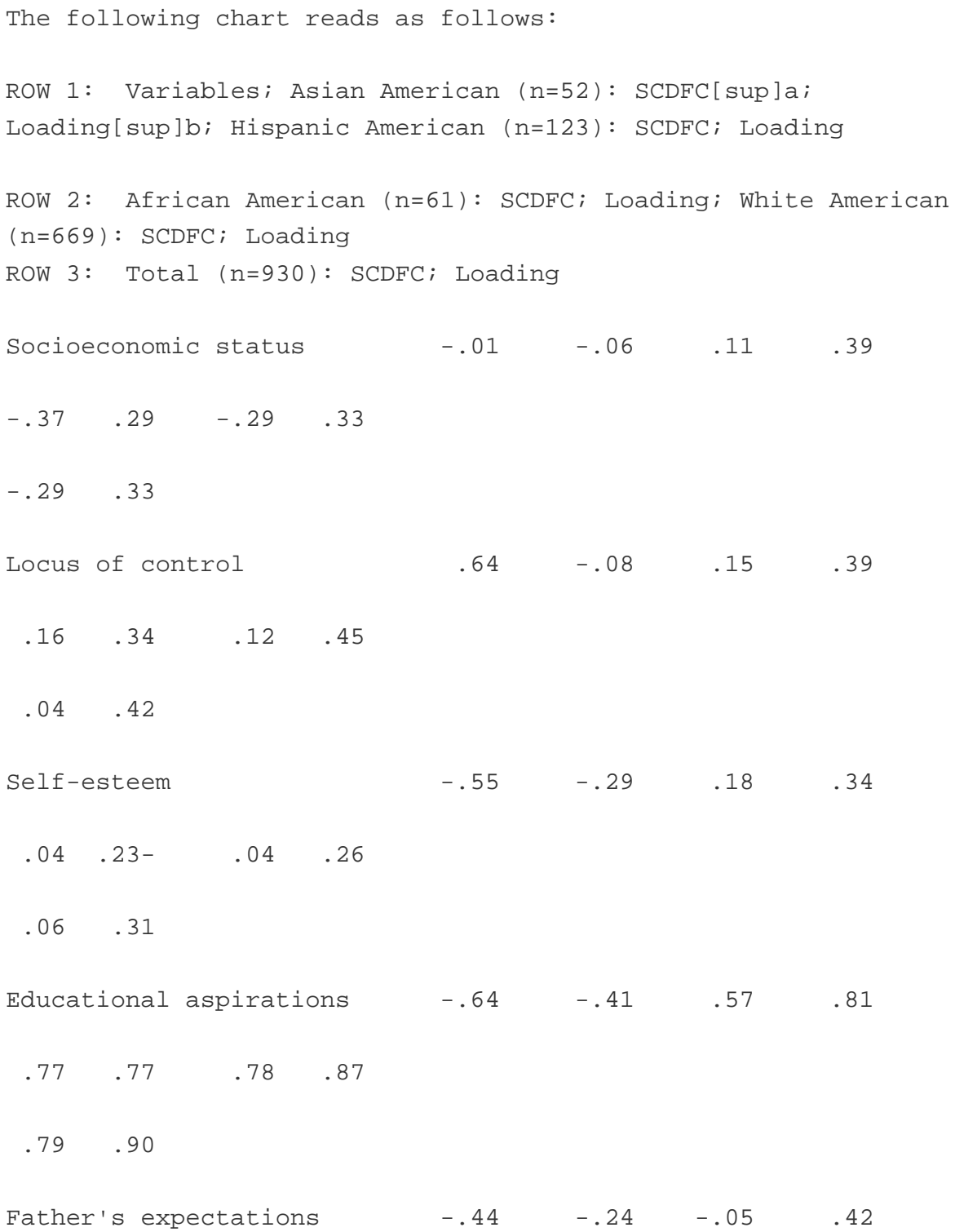


$\begin{array}{llll}-.32 & .25 & -.07 \quad .45\end{array}$

$-.07 \quad .47$

Mother's expectations

$\begin{array}{lll}.75 & -.11 & .15\end{array}$

.41

$\begin{array}{llll}.47 & .49 & .16 \quad .49\end{array}$

$.19 \quad .52$

Math proficiency

$\begin{array}{llll}.36 & -.11 & .28 & .39\end{array}$

$\begin{array}{llll}.57 \quad .55 \quad .06 & .50\end{array}$

$.07 \quad .48$

Reading proficiency

$\begin{array}{llll}.02 & -.20 & .13 & .31\end{array}$

$\begin{array}{llll}-.32 & .26 & -.02 & .40\end{array}$

$-.03 \quad .37$

Science quartile

$\begin{array}{llll}-1.37 & -.51 & -.10 & .26\end{array}$

$\begin{array}{llll}.19 & .42 \quad .31 & .59\end{array}$

$.25 \quad .52$

Self-reported GPA[c]

$-.31 \quad .28$

.47

$\begin{array}{llll}.02 & .31 & .07 \quad .49\end{array}$

$.12 \quad .50$

Number of siblings

$\begin{array}{llll}.50 & .19 & -.23 & -.37\end{array}$

$\begin{array}{llll}.07 & -.16 & -.29 & -.31\end{array}$

$-.25-.31$

Eigenvalue

$\begin{array}{lll}1.27 & -- & .73\end{array}$

1.75

.48

.50

Canonical correlation

.75

.65

.80

.57

.58

Wilks's lambda

.44

.58

.36

.68

.67

Chi square

36.46

$--\quad 63.08$

54.15

257.70 


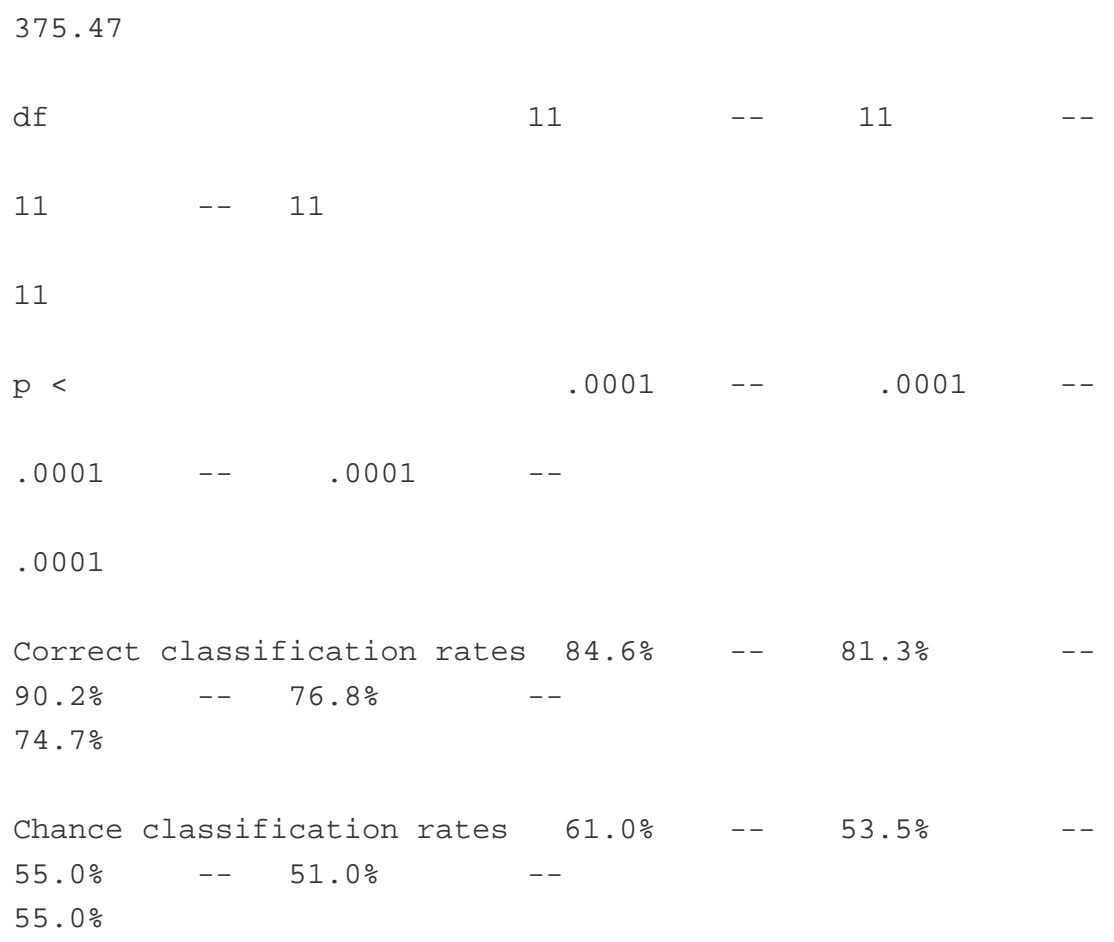

a Standardized canonical discriminant function coefficients. b Pooled within-groups correlations between discriminating variables and canonical discriminant functions. C Grade point average.

\section{References}

Almquist, E. (1974). Sex stereotypes in occupational choice: The case for college women. Journal of Vocational Behavior, 5, 13-21.

American Association of University Women (1991). Shortchanging girls, shortchanging America. Washington, DC: Author.

Baker, D. R. (1987). The influence of role-specific self-concept and sex-role identity on career choices in science. Journal of Research in Science Teaching, 24(8), 739-756.

Bern, S. L. (1974). The measurement of psychological androgyny. Journal of Consulting and Clinical Psychology, 42, 155-162.

Berman, Y. (1972). Occupational aspirations of 545 female high school seniors. Journal of Vocational Behavior, 2, 173-177.

Blau, P.M., \& Duncan, O. D. (1967). The American Occupational Structure. New York: Wiley.

Brooks, L. (1984). Counseling special groups: Women and ethnic minorities. In D. Brown \& L. Brooks (Eds.), Career choice and development. (pp. 355-368). San Francisco, CA: Jossey-Bass.

Dick, T. P., \& Rallis, S. F. (1991). Factors and influences on high school students' career choices. Journal for Research in Mathematics Education, 22, 281-292.

Duran, B. J., \& Weffer, R. E. (1992). Immigrants' aspirations, high school process, and academic outcomes. American Educational Research Journal, 29, 163-181.

Fitzgerald, L. F., \& Betz, N. E. (1983). Issues in the vocational psychology of women. In W. B. Walsh \& 
J. H. Osipow (Eds.), Handbook of vocational psychology (Vol. 1, pp. 83-159). Hillsdale, NJ: Erlbaum.

Fitzpatrick, J. L., \& Silverman, T. (1989). Women's selection of careers in engineering: Do traditionalnontraditional differences still exist? Journal of Vocational Behavior, 34, 266-278.

Hanson, S. L., \& Ginsburg, A. L. (1988). Gaining ground: Values and high school success. American Educational Research Journal, 25, 334-365.

Haring, M. J., \& Beyard-Tyler, K. C. (1984). Counseling with women: The challenge of nontraditional careers. The School Counselor, 31, 301-309.

Hayes, R. (1985). Gender nontraditional or sex atypical or gender dominant or. . research: Are we measuring the same thing? Journal of Vocational Behavior, 29, 79-88.

Herr, E. L. (Ed.). (1992). The school counselor and comprehensive programs for work-bound youth. Alexandria, VA: American Counseling Association/National Occupational Information Coordinating Committee.

Herr, E. L., \& Cramer, S. H. (1988). Career guidance and counseling through the life span: Systematic approaches (3rd ed.). New York: HarperCollins.

Hilton, T. L., \& Lee, V. E. (1988). Student interest and persistence in science: Changes in the educational pipeline in the last decade. Journal of Higher Education, 59, 510-526.

Holland, P. W., \& Thayer, D. T. (1986). Differential item functioning and the Mantel-Haenszel procedure. (ETS Research Report No. 86-31). Princeton, NJ: Educational Testing Services.

Jacobson, C. J. (1980, April). New challenges for women workers. AFL-CIO American Federationist, 1-8.

Kerckhoff, A. C. (1989). On the social psychology of social mobility processes. Social Forces, 68, 17-25.

Klecka, W. R. (1980). Discriminant analysis. Beverly Hills, CA: Sage.

MacCorquodale, P. (1984). Self image, science and math: Does the image of the "scientist" keep girls and minorities from pursuing science and math? Paper presented at the annual meeting of the American Sociological Association, San Antonio, TX.

Maple, S. A., \& Stage, F. IC (1991). Influences on the choice of math/science major by gender and ethnicity. American Educational Research Journal, 28, 37-60.

Mau, W. C. (in press). Educational planning and academic achievement of middle school students: A racial/ cultural comparison. Journal of Counseling \& Development.

Mazen, A.M., \& Lemkau, J.P. (1990) Personality profiles of women in traditional and nontraditional occupations. Journal of Vocational Behavior, 37, 46-59. 
McBride-Bass, J. (1993). Women's work no moro: Nontraditional programs bring more women into high-tech fields. Vocational Education Journal, 68(3), 22-23.

McKenna, A. E., \& Ferrero, G. W. (1991). Ninth-grade students' attitudes toward nontraditional occupations. The Career Development Quarterly, 40, 168-181.

Murrell, A. J., Frieze, I. H., \& Frost, J. L. (1991). Aspiring to careers in male- and female-dominated professions. Psychology of Women Quarterly, 15, 103-126.

National Center for Educational Statistics. (1981). National longitudinal study of the high school class of 1972: Study report update. Washington, DC: U.S. Department of Education.

National Center for Educational Statistics. (1982). High school and beyond 1980 Sophomore cohort: First follow-up (Report No. 83-214). Washington, DC: U.S. Department of Education.

National Center for Educational Statistics. (1990a). National education longitudinal study of 1988, base year: Student component data file user's manual (Report No. 90-464). Washington, DC.' U.S. Department of Education.

National Center for Educational Statistics. (1990b). National education longitudinal study of 1988: Base year sample design report (Report No. 90-463). Washington, DC: U.S. Department of Education.

National Center for Educational Statistics. (1991). Psychometric report for the NELS:88: Base year test battery (Report No. 91-468). Washington, DC: U.S. Department of Education.

Nevill, D. D., \& Schlecker, D. (1988). The relation of self-efficacy and assertiveness to willingness to engage in traditional/nontraditional career activities. Psychology of Women Quarterly, 12, 91-98.

Otto, L. B., \& Hailer, A. O. (1979). Evidence for a social-psychological view of the status attainment process. Social Forces, 57, 887-914.

Pryor, R. G. L. (1981). Interests and values as preferences. Australian Psychologist, 16, 258-272.

Pryor, R. G. L., \& Taylor, N. B. (1986). On combining scores from interest and value measures for counseling. The Vocational Quarterly, 34, 178-187.

Rea-Poteat, M. B., \& Martin, P. F. (1991). Taking your place: A summer program to encourage nontraditional caroer choices for adolescent girls. The Career Development Quarterly, 40, 182-188.

Riley, R. W. (1993, May 17). Strong effort needed to upgrade education. Wichita Eagle, p. 13A.

Rosenberg, M. (1965). Society and the adolescent self-image. Princeton, NJ: Princeton University Press.

Rubenfeld, M. I., \& Gilroy, F. D. (1991). Relationship between college women's occupational interests and a single-sex environment. The Career Development Quarterly, 40, 64-71. 
Sewell, W. H., \& Hauser, R. M. (1980). The Wisconsin study of social psychological factors in aspiration and achievements. Research in Sociology of Education and Socialization, 1, 59-99.

Sloat, B. F. (1990). Perspectives on women and the sciences. LSA magazine, 13, 13-17.

Smith, E. J. (1980). Career development of minorities in nontraditional fields. Journal of Non-White Concerns, 8 , 141-156.

SPSS. (1990) SPSS advance statistics user, guide. Chicago, IL: Marija Norusis/SPSS.

Stewart, H. R. (1989). Job satisfaction of women in nontraditional occupations. Journal of Employment Counseling, 26, 26-34.

Super, D. E. (1969). Vocational development theory. The Counseling Psychologist, 1, 2-30.

Tabachnick, B. G., \& Fidell, L. S. (1989). Using multivariate statistics (2nd ed.). New York: Harper \& Row.

U.S. Department of Labor. (1988). Opportunity 2000: Creative affirmative action strategies for a changing workforce. Indianapolis, IN: Hudson Institute. 